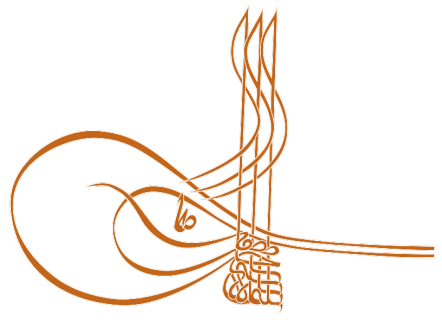

www.turkishstudies.net/language
Turkish Studies - Language and Literature

eISSN: $2667-5641$

Research Article / Araștırma Makalesi

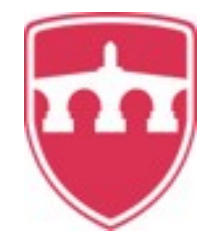

INTERNATIONAL

BALKAN

UNIVERSITY

Sponsored by IBU

\title{
Behcetü'l-Hadâik'taki Fiilimsiler ve Bunların Kullanılışı Üzerine Karşılaştırmalı Bir Değerlendirme
}

\author{
A Comparative Evaluation of Gerundial and Their Usage in Behcetu'l-Hadaik
}

\author{
Türker Barış Bulduk*
}

\begin{abstract}
The works that contain the language features belonging to Eastern Turkish and Western Turkish are called mixed language works. Behcetü'l-Hadâik is one of the works that is described as mixed-language together with Kissa-yı Yusuf and Feraiz Book. Behcetü'l-Hadâik is a book of counsel. This copy was found by Sadettin Buluç. Mustafa Canpolat published the work. Comparative studies showing the language features of Eastern Turkish and Western Turkish related to Behcetü'l-Hadâik and other mixed language works and researches based on statistical data were not conducted. Behcetü'l-Hadâik is a book oftensively in Turkish since Old Turkish. After the detection of the gerundial in Behcetü'l-Hadâik, it is aimed to examine the use of these gerundials in Karahan, Khwarezm, Kipchak and Old Anatolian Turkish. In this context, the Bursa copy of the work written by an unknown author, which was copied by Abu Bakr bin Sheikh Ali bin Muhammad in H 703 / M 1303 and published by Mustafa Canpolat, was evaluated and it was observed that many gerundial works used in the historical periods of Turkish were also used in Bursa copy. Although the work was retained at the beginning of the 14th century, more data specific to Karahan, Khwarezm and Kipchak Turkish were found. This suggests that the work was translated from Eastern Turkish to Western Turkish or written by someone who later migrated to Anatolia.
\end{abstract}

Stractured Abstract: Behcetü'l-Hadâik is the text that best represents mixed language works. Although the author and writing date of the book is not known, it is estimated that it was written from the end of the 12th century and the beginning of the 13th century.

Until today, almost all of the studies on Behcetü'l-Hadâik have taken into account the Bursa copy. This copy was found by Sadettin Buluç. Mustafa Canpolat published the work. The data in this study was taken from Behcetü'l-Hadâik fî Mevizati'l-Halâik prepared by Mustafa Canpolat and published by TDK. In our study, the gerundial affixes in this work were evaluated. gerundial is one of the essential elements of Turkish and is one of the busiest additions used in all historical periods of Turkish since Old Turkish. Many of the gerundial suffixes, as with many other Turkish suffixes, either fell out of use or underwent some sound

\footnotetext{
* Dr. Öğr. Üyesi, Adıyaman Üniversitesi, Fen Edebiyat Fakültesi, Türk Dili ve Edebiyatı Bölümü, Yeni Türk Dili Assist. Prof., University of Adiyaman, Faculty of Science and Literature, Turkish Language and Literature ORCID 0000-0002-0423-837X turkerbulduk@gmail.com
}

Cite as/ Atıf: Bulduk, T. B. (2020). Behcetü'l-Hadâik'taki fiilimsiler ve bunların kullanılıșı üzerine karşılaştırmalı bir değerlendirme, Turkish Studies - Language, 15(1), 65-78. https://dx.doi.org/10.29228/TurkishStudies.40507

Received/Geliş: 06 January/Ocak 2020

Accepted/Kabul: 25 March/Mart 2020

Checked by plagiarism software

Copyright (C) INTAC LTD, Turkey

Published/Yayın: 30 March/Mart 2020

CC BY-NC 4.0 
changes. Precise information on gerundial use or sound changes can only be accessed through written sources. Behcetü'l-Hadâik is one of the important written sources in the historical adventure of Turkish.

In this study, the gerundial in Behcetü'l-Hadâik, which has an important place in Turkish in terms of language features, is emphasized. In our study, starting from Köktürk scripts, we will examine the usage of gerundial affixes in Behcetü'l-Hadâik which are used extensively in all historical periods of Turkish. We will also focus on the similarities of these uses of gerundials in Karahan, Kipchak, Khwarezm and Old Anatolian Turkish. In this way, with statistical data, we will explain the resemblance of gerundials in Behcetü'l-Hadâik, which is one of the mixed language works, with the historical Turkish period.

The use of gerundial affixes in Behcetü'l-Hadâik, which is accepted as the best representative of mixed linguistic works among mixed-language works, confirms this characterization. As a matter of fact, there are uses specific to both Karahan, Khwarezm and Kipchak Turkish and Old Anatolian Turkish. It is possible to list them as follows:

a. The gerundials used commonly both in Karahan and Turkish and Behcetü'l-Hadâik are : - $m A$, $m A k,-I S ̧ /-U s,,-r /-A r /-I r /-U r,-m A s,-A s I,-D U k,-m I s,,-A n /-g A n,-g U c I / g U c ̧ I,-g U s I,-m A d I n,-b A n /-U b A n,-p /-$ $I p /-U p$, -ken, $-A /-I /-U$. The number of these suffixes is 27.

Among these suffix $-g U c I /-g U_{c} I$ and $-g U_{S I}$ are only common both in Karahan Turkish and Behcetü'l-Hadâik

*Sen bir ķulsañ fermān $d u t g \dot{u} \iota c ̧$ ve men bir ķulmen fermān yirine ketüriçi (BH, 226).

*Tañrınuñ baśir adı başlaġusı durur, sin semị adı başlag்usı durur (BH, 302).

b. There are also gerundials used commonly both in Khwarezm Turkish and Behcetü'l-Hadâik these are, $-m A,-m A k,-I_{S ̧} /-U_{s ̧, ~}-r /-A r /-U r,-m A s,-A s I /-G A s I,-D U k,-m I$ ş, $-A n /-g A n,-m A d I n,-b A n /-U b A n,-I n c ̧ A,-p /-$ $I p /-U p$, -ken, $-A /-U$, $-d I$ erse. The number of these suffixes is 25 .

Among these suffixes $-G A s I$, $-I n c ̧ A$ and $-d I$ erse are only common in Khwarezm Turkish and Behcetü'l-Hadâik

*Dökilgesi dükel yılduz bu felekden

Andayuķ kim yag̉ar erse kökden dolu (BH, 71).

*Biz bu işi bitürinçe atam sü dirsün (BH, 151).

*Ķaçan kim Peyġāmber dünyādan dulındı erse ol og̉lan daşra çıķdı (BH, 124).

c. Gerundial suffixes, which are commonly used in Kipchak Turkish and Behcetü'l-Hadâik, are as follows: $-m A,-m A k,-I s ̧ /-U s,-r /-A r /-I r /-U r,-m A s,-I c ̧ A k,-A s I,-D U k,-m I s ̧,-A n /-g A n,-b A n,-p /-I p /-U p,-$ $d U k c ̧ A$, $-k e n,-A /-I /-U$. The number of these suffixes is 24 .

Among these suffixes only $-I c ̧ A k$ is common in Kipchak Turkish and Behcetü'l-Hadâik.

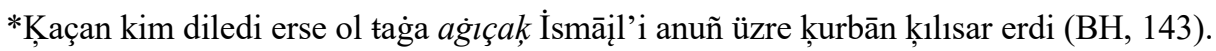

d. The Gerundials, which are commonly used in Old Anatolian Turkish and Behcetü'l-Hadâik, can be listed as follows: $-m A$, $-m A k,-I s ̧ /-U s,-m A k l I k,-r /-U r,-I c A k,-A s I,-d U k,-m I s ̧,-A n,-m A d I n,-d U g I n c A$, $U b A n,-U p,-d U k c ̧ A$, $-k e n,-A /-I /-U,-A l I,-A l d A n$. The number of these suffixes is 23.

There is no usage of $-m A s$ verbal adjective as $-m A z$. With this feature, it shows resemblance with Karahan, Khwarezm and Kipchak Turkish.

The verbal adjective of $-d U k$ is in the form of consonant harmony in Behcetü'l-Hadâik'ta. The same annex is out of harmony in Old Anatolian Turkish. In addition, with this feature this annex is used in Karahan, Khwarezm and Kipchak Turkish.

The verbal adjective of $-A n$ is also used in Old Anataolian Turkish. However, in Behcetü'l-Hadâik, this form of the annex was found together with $-g A n$. This usage coincides with Karahan, Khwarezm and Kipchak Turkish.

The verbal adverb of -UbAn which can be found in Old Anatolian Turkish has a similar usage as $b A n$ in Karahan, Khwarezm and Kipchak Turkish and this is also common with Behcetü'l-Hadâik. 
The rounded vowel of $-U p$ which can be found in Old Anatolian Turkish and used as verbal adverb has a usage as - $p$ in Karahan, Khwarezm and Kipchak Turkish and Behcetü'l-Hadâik.

The verbal adverb of $-U$ gives meaning of $-A r A k$ to the speech. The use of this annex in this form was found in Karahanl, Khwarezm and Kıpçak Turkish and Behcetü'l-Hadâik.

In Behcetü'l-Hadâik, gerundials which are used jointly has been identified and the numbers are as follows: Karahan Turkish is 2; Khwarezm Turkish is 3; Kipchak Turkish is 1 and Old Anatolian Turkish is 4. In addition, there were 7 gerundial in Behcetü'l-Hadâik, which are used jointly in Karahan, Kharezm and Kipchak Turkish. In Behcetü'l-Hadâik, gerundial specific uses in Old Anatolian Turkish are less than in Karahanl, Khwarezm and Kıpçak Turkish. This situation reinforces the possibility that the Bursa copy of Behcetü'l-Hadâik, which was copied at the beginning of the 14th century, was written by the Turks who migrated to Anatolia, not by the people who were born and raised in Anatolia.

Key Words: Philology, Gerundial, Behcetü'l-Hadâik, Karahan Turkish, Kipchak Turkish, Old Anatolian Turkish.

Öz: İçerisinde Doğu Türkçesi ve Batı Türkçesine ait dil özellikleri barındıran eserlere karışık dilli denmektedir. Behcetü'l-Hadâik da Kıssa-yı Yusuf ve Feraiz Kitabı ile birlikte karışık dilli olarak nitelendirilen eserlerden biridir. Behcetü’l-Hadâik, bir öğüt kitabıdır. Eser, Sadettin Buluç tarafindan bulunmuştur. Eserin bütününün neşrini Mustafa Canpolat yapmıştır. Behcetü’l-Hadâik ve diğer karışık dilli eserlerle ilgili Doğu Türkçesi ve Batı Türkçesine ait dil özelliklerini gösteren karşılaştırmalı incelemeler ile istatistiki verilere dayanan araştırmalar yapılmamışıır. Dolayısıyla bu eserlerin niçin karışık dilli kabul edildikleri ile ilgili somut veriler henüz ortaya konmamıştır. Bu çalışmada öncelikle Behcetü'l-Hadâik eserindeki fiilimsiler tespit edilecektir. Fiilimsiler, Türkçenin asli unsurlarından biridir ve Eski Türkçeden bu yana Türkçede işlek bir biçimde kullanılagelmişlerdir. Behcetü'l-Hadâik'taki fiilimsiler tespit edildikten sonra, bu fiilimsilerin Karahanlı, Harezm, Kıpçak ve Eski Anadolu Türkçesindeki kullanımlarını incelemek amaçlanmaktadır. Bu bağlamda, yazarı bilinmeyen eserin Ebu Bekr bin Şeyh Ali bin Muhammed tarafindan H 703/M 1303 yllında istinsah edilen ve Mustafa Canpolat tarafından neşredilen Bursa nüshası değerlendirilmiş ve Türkçenin tarihi dönemlerinde kullanılan birçok fiilimsinin eserin Bursa nüshasında da kullanıldığı görülmüştür. Eser, 14. yüzyılın başlarında istinsah edilmesine rağmen eserde Karahanlı, Harezm ve Kıpçak Türkçesine özgü daha fazla veri tespit edilmiştir. Bu durum, eserin Doğu Türkçesinden Batı Türkçesine tercüme edildiğini ya da Anadolu'ya daha sonra göç eden birisi tarafından yazıldığını düşündürmektedir.

Anahtar Kelimeler: Filoloji, Fiilimsi, Behcetü’l-Hadâik, Karahanlı Türkçesi, Harezm Türkçesi, Kıpçak Türkçesi, Eski Anadolu Türkçesi.

\section{Giriş}

11. yüzyıldan başlayarak 13. yüzyıla kadar devam eden süreçte başını Türklerin çektiği İslam uygarlığı, Haçlı Seferleri ve Moğol İstilası gibi iki büyük askeri harekât ile uğraşmak zorunda kalmıştır. Bu iki büyük askeri harekât, siyasi, tarihi ve kültürel anlamda Anadolu ve Ortadoğu coğrafyasında derin izler bırakmıştır. Özellikle Orta Asya'dan başlayan Moğol İstilası'ndan kurtulmak için yaşadığı yerlerden göç etmek zorunda kalan Türkler, geldikleri yerlere dil özelliklerini de beraberlerinde getirmişlerdir. Birçok Türk boyunun birbirinden farklı özellikler taşıyan dil özelliklerinin etkileşimiyle Türkçenin birçok farklı ağzı ortaya çıkmıştır.

1071 Malazgirt Zaferi'nden sonra Anadolu'yu yurt edinmeye başlayan Türkler uzun y1llar süren siyasi mücadeleler nedeniyle 11-13. yüzyıllar arasında çok fazla yazılı eser üretememişlerdir ya da yazılan eserler siyasi belirsizlikler ve istilalar neticesinde yok edilmişlerdir. 11-13. yüzyıllar arasındaki siyasi karışıklıklardan ötürü o dönemde yazılan az sayıda eser günümüze ulaşabilmiştir. Behcetü'l-Hadâik, Kıssa-yı Yusuf ve Feraiz Kitabı da bu dönemden kalan eserlerdendir. Bu eserlere, içerisinde Doğu ve Batı Türkçesine ait dil özellikleri olduğu için karışık dilli denmiştir. 
Eserlerdeki karışık dilliliğin nedenleri üzerinde farklı görüşler bulunmaktadır. Konuyla ilgili Şinasi Tekin Feraiz Kitabı incelemesinde, Eski Anadolu Türkçesi yazı dilinin Eski Türkçenin etkisiyle ortaya çıkmadığını savunur. Tekin, karışık dilli kabul edilen eserleri Orta Asya'nın Türk ve İran asıllı bilginlerinin yazdıklarını, siyasi karışıklıklar nedeniyle özellikle 12. yüzyıldan sonra Anadolu'ya göç etmek zorunda kalan bu bilginlerin Anadolu'da konuşulan Türkçeyi hemen öğrenemediklerini ve zamanla Orta Asya'dan getirdikleri Türkçe ile Anadolu'da konuşulan Türkçeyi yan yana kullanmak zorunda olmalarına bağlar.

Konuyla ilgili bir başka görüş de Alman Türkolog Doerfer'e aittir. Doerfer, Horasan Türkçesinin hem Doğu'ya hem de Batı'ya ait özellikler taşıdığını ve Horasan Türkçesinin karışık dilli eser sorununu çözmekte kullanılabilecek anahtar bir şive olduğunu savunmuştur. Bu iddiayı, Horasan Türkçesinin bir alt diyalektiği olarak gördüğü Özbek Oğuzcasındaki lehçe karışıklığına ve 13. yüzyılda Anadolu'ya birçok Türk'ün bu bölgeden gelmesine dayandırmıştır. Doerfer'e göre, 13. yüzyılda Horasan'da birbirine karışan Oğuz ve Özbek ortak dil unsurları, yazılı metinlere de yansımış, böylece karışık dilli eserler ortaya çıkmıştır (Akar, 2005: 245-246).

Reşit Rahmeti Arat ise “Anadolu Yazı Dilinin Tarihi İnkişâfına Dair” makalesinde Türk coğrafyasında gerçekleşen siyasi olaylar ve bunların neticesinde ortaya çıkan göçler ile Türklerin yeni kültür merkezleri kurduklarını ve bu merkezlerde kendilerine özgü birkaç yazı diline sahip olduklarını söyler. Arat, 13. yüzyıldan önce hem Harezm hem de Anadolu'daki yazı diline işaret etmekte ve her iki coğrafyada da fazla eserin elimizde olmadığını vurgulamaktadır. Karışık dilli eserlerin yeni yazı dillerinin Eski Türkçeden ayrılıp oluşmaya başladıkları bir geçiş devresinin yani 11-13. yüzyılların mahsulü olduğu görüşünü savunan Arat, Türk dilinin ve özellikle Anadolu yazı dilinin tarihi gelişiminde bir geçiş aşaması olarak kabul ettiği karışı devreye ait bu eserlerin dikkatle taranması ve araştırılması gerektiğine dikkat çekmektedir.

Karışık dilli eserlerin aslında Doğu Türkçesinden Batı Türkçesine yapılan tercümeler olduğu ve mütercimlerin metni tercüme ederken mensur kısımları çevirip manzum kısımlara müdahale etmediği şeklinde fikirler de ileri sürülmektedir. Yukarıdaki görüş ve iddiaların ne derece doğru olduğu ancak metinler üzerinde sistematik, karşılaştırmalı ve istatistiki dil verilerine dayanarak yapılan çalışmalarla anlaşılabilir (Türk, Doğan ve Şerifoğlu, 2018: 23).

Karışık dilli eserler ile ilgili karşılaştırmalı dil çalışmalarının sayısı fazla değildir. Konu ile ilgili Türker Barış Bulduk "Behcetü'l-Hadâik ve Kıssa-yı Yusuf'taki Kip Ekleri Üzerine Karşılaştırmalı Bir İnceleme" adlı makalesinde, Behcetü'l-Hadâik ve Kıssa-yı Yusuf'taki kip eklerini Karahanlı, Kıpçak, Harezm ve Eski Anadolu Türkçesindeki kip ekleri ile karşılaştırmış ve istatistiki veriler ortaya çıkarmıştır.

Karışık dilli eserleri en iyi temsil eden metin Behcetü'l-Hadâik’tır. Kitabın yazarı ve yazılış tarihi kesin olarak bilinmemekle birlikte dil özelliklerinden 12. yüzy1lın sonu ile 13. yüzyılın başında yazılmış olduğu tahmin edilmektedir. Eserin bilinen dört nüshası vardır. Birinci nüsha Bursa Orhan Kitaplı̆̆g’ndadır ve üzerinde istinsah tarihi olarak H 703/M 1303 kaydı vardır. Diğer nüsha İstanbul Süleymaniye Kütüphanesi İbrahim Efendi Kitaplığı'nda yer almaktadır. Bu nüshanın yazarı Nâsırüddin Ahmed bin Muhadded'dir ve istinsah tarihi olarak H 880/M 1475 kayd1 vardır (Akar, 2005: 246). Üçüncü nüsha Ankara Üniversitesi İlahiyat Fakültesi Kitaplığı'ndadır. Bu nüshada eserin sadece bir bölümü olan 140 varak vardır. Eserde müellif adı, istinsah tarihi, yeri ve müstensih adı kayıtlı değildir. $\mathrm{Bu}$ nüshanın dili 15. veya 16. yüzyıl Anadolu Türkçesine çevrilmiştir. Ses özellikleri bakımından üç nüshanın en yenisi olduğu anlaşılmaktadır. Eserin dördüncü nüshası ise Berlin Marburg nüshası olarak geçmektedir. 291 varaktır ve H 429/M 1429'da Yusuf bin Süleyman el-Osmani tarafindan istinsah edilmiştir (Canpolat, 2018: 19).

Bugüne kadar Behcetü'l-Hadâik üzerine yapılan çalışmaların neredeyse tamamında Bursa nüshası dikkate alınmıştır. Bu nüsha Sadettin Buluç tarafından bulunmuştur. Mustafa Canpolat ise eserin neşrini yapmıştır. Bu çalışmadaki veriler, Mustafa Canpolat'ın hazırladığı ve TDK 
tarafından neşredilen Behcetü'l-Hadâik fî̀ MevǾizati'l-Halâik eserinden alınmıştır. Çalışmamızda, bu eserdeki fiilimsi ekleri değerlendirilmiştir. Fiilimsiler Türkçenin asli unsurlarından biridir ve Eski Türkçeden bu yana Türkçenin bütün tarihi dönemlerinde kullanılmış en işlek eklerindendir. Fiilimsi eklerinin birçoğu, Türkçenin diğer birçok eklerinde olduğu gibi, zamanla ya kullanımdan düşmüş ya da birtakım ses değişikliklerine uğramıştır. Fiilimsilerdeki kullanımdan düşme veya ses değişiklikleri ile ilgili kesin bilgilere ancak yazılı kaynaklar üzerinden erişilebilir. Behcetü’lHadâik da Türkçenin tarihi serüveninde önemli yazılı kaynaklardan biridir.

Bu çalışmada, dil özellikleri bakımından Türkçede önemli bir yere sahip olan Behcetü'lHadâik eserindeki fiilimsiler üzerinde durulmuştur. Çalışmamızda, Köktürk Kitabeleri'nden başlayarak Türkçenin bütün tarihi dönemlerinde işlek bir biçimde kullanılan fiilimsi eklerinin Behcetü'l-Hadâik'taki kullanımları incelenecektir. Ayrıca bu kullanımların Türkçenin tarihi dönemlerinden Karahanlı, Kıpçak, Harezm ve Eski Anadolu Türkçesindeki fiilimsilerin hangileriyle ne denli benzerlik gösterdiği üzerinde durulacaktır. Böylelikle karışık dilli eserlerden biri olan Behcetü'l-Hadâik'taki fiilimsilerin Türkçenin hangi tarihi dönemiyle benzeștiğini istatistiki verilerle ortaya konacaktır.

\section{2. İnceleme}

\subsection{Behcetü'l-Hadâik'ta Fiilimsiler}

\subsubsection{Behcetü'l-Hadâik'taki İsim-Fiiller:}

$-\mathbf{m A}$ :

Türkçenin bütün tarihi dönemlerinde şeklini muhafaza eden bu ek, fiillere gelerek iş isimleri yapar. $\mathrm{BH}^{1}$ de de aynı kullanım özelliğini devam ettirmiştir:

*Müfessirler aydurlar, anuñ içinde degmesi bir dürlü söz aydurlar (BH, 191).

*Yūsuf, Yaǿḳūb'a k̦avuşma vaḳtında altun ћazịnesin açdı (BH, 197).

*Şerįøá hä̈kminçe eli şeşilmeye hükümlü boldı ve desturlu boldı (BH, 241).

-mAk:

Mastar eki de denen bu ek, fiil kök ve gövdelerine gelerek hareket isimleri yapar. Türkçenin tarihi dönemlerinde aynı kullanım özelliğini devam ettiren ek, BH'de de sıklıkla görülmüş̧ür:

*Bir maǿnicis śubh yiri agaarmaḳı bolur (BH, 128).

*Tañrı birle bāzirgānlik k̦ılmak, endịsesi durur, köñüllerinde Tañrı’ya dönmek durur (BH, 174).

*Yakınlıkia degmek durur, dostluka irmek durur (BH, 184).

-Iş, -Uş:

İş ve nesne isimleri yapan bu ek Eski Türkçede -ş şeklindeydi (Ergin, 2003: 187). Eski Anadolu Türkçesinde düz ve yuvarlak ünlülü olarak kullanılan bu ek çoğunlukla dudak uyumuna dâhil olmuştur. BH'de de düz ve yuvarlak ünlülü kullanılan bu isim-fiil eki, bazı yerlerde dudak uyumu dışında kalmıştır:

*Kacarsavus kurtılış yok, eglensevüs diñleniş yok (BH, 190).

*Muhammed'i anda iltişsin āşikārā ḳıldı ve dönüşin āşikāre ḳılmadı (BH, 182).

\footnotetext{
${ }^{1}$ Eser adı makalede çok kullanıldığından makalenin inceleme bölümünde Behcetü’l-Hadâik yerine BH kullanılacaktır.
} 
*Barışı iżāfeti Tañrı durur, inişi iżāfeti Muśtafā durur (BH, 182).

-mAklIk:

Eski Anadolu Türkçesinde görülen bu ek, - $m A k$ mastar eki ile aynı fonksiyondadır (Şahin, 2018: 71). BH'de sıklıkla kullanılmıştır:

*Ve KaǾbe yapılup tamām bolmaķliğı bu on kün içinde erdi (BH, 134).

*Oruç durmaḳlı cān diñlenmeklik durur (BH, 88). (BH, 139).

*Degül durur sizüñ yaradılmaķlığıñz dak,ı kıyāmette k,opmak,lıķıñı bir illā bir nefs içün

\subsubsection{Behcetü'l-Hadâik'taki Sıfat-Fiiller:}

\section{-r/-Ar/-Ir/-Ur}

Geniş zaman ifade eden sıfat-fiillerden biridir. Eski Türkçeden beri varlığını devam ettiren bu ek, Türkçenin tarihi dönemlerinde $-r$ ekinin farklı ünlülerle birleşmesi şeklinde kullanılagelmiştir. Ek, Karahanlı ve Kıpçak Türkçesinde -r/-Ar/-Ir/-Ur şeklindedir (Hacıeminoğlu, 2019: 165; Argunşah ve Yüksekkaya, 2019: 345). Harezm Türkçesinde dar-düz ünlülü -Ir kullanımı dışındaki -r/-Ar/-Ur kullanımları devam etmiştir (Argunşah ve Yüksekkaya, 2019: 206). Eski Anadolu Türkçesinde birçok ekteki yuvarlaklaşma eğilimi - $r$ sıfat-fiil ekine de yansımış ve ek sadece -(U) $r$ şeklinde kullanılmıştır (Gülsevin, 2011: 124).

BH'de bu ekin kullanımı Karahanlı ve Kıpçak Türkçesindeki gibidir: (BH, 208).

*Yörir ayak, dutar el k̦ıldum, işidür k̦ulak,, söyler dil k̦ıldum, körür köz, bilür köñül k,ıldum (BH, 112).

* Uçar k,uşlar, yörir keyikler, dįvler ve cinniler ve ins ve eser yiller k̦amu aña fermān boldı

\section{$-\mathbf{m A s}$}

Menfi geniş zaman sıfat-fiil eki olan bu ek eskiden beri geniş ölçüde kullanılagelmiştir. $m A$ olumsuzluk eki ile $-z$ sıfat-fiil veya isim yapma ekinin birleşmesinden ortaya çıkmıştır (Ergin, 2003: 336). Karahanlı, Harezm ve Kıpçak Türkçesinde - $m A z$, $-m A s$ şekillerinde kullanılan ekin, Eski Anadolu Türkçesinde sadece - $m A z$ şekli görülür.

Bu ekin Karahanlı, Harezm ve Kıpçak Türkçesinde görülen - $m A s$ şekli BH'de de tespit edilmiştir. - $m A z$ şekli ise BH'de hiç kullanılmamıştır:

*Bu kerekmes yirde harf k̦omaķa iǿcāz lāzım durur (BH, 284).

*Ne meñlü ol kimse kim aña degse, endāzesüz niǿmet bulsa, dükenmes baylık, bulsa, osanmas cift bulsa (BH, 230).

*Eger sizlerde Peyġāmberi sever barısa anuñ konugina hürmet dutuñ, evüñizi arıduñ yaramas işden, maǾdeñüzi arıduñ ĥarām aşdan (BH, 67).

\section{-IçAk}

Batı Türkçesinin ilk devirlerinde uzun zaman kullanılıp sonradan unutulan bir zarf-fiil ekidir. Eski Anadolu Türkçesinde tamamıla ve geniş ölçüde, Osmanlıcada ise bir müddet kullanılmıştır. Fonksiyon bakımından -IncA/-UncA ekinden farksızdır (Ergin, 2003: 344). Bu zarffiil eki, Kıpçak Türkçesinde -IçAk/-UçAk (Argunşah ve Yüksekkaya, 2019: 347); Eski Anadolu Türkçesinde -(y) IcAk şeklindedir (Gülsevin, 2011: 125). 
BH'de bu ek, hem Kıpçak Türkçesindeki -IçAk hem de Eski Anadolu Türkçesindeki -IcAk şeklinde kullanılmış ve zarf-fiil olarak cümleye zaman anlamı katmıştır:

*Ve ol k̦ızlar kim anadan dogicak, ǾArablar anı dirile külidiler (BH, 201).

*Minüm adum söylenicek baķar, anuñ içün durur (BH, 222).

*Hadicce aydur: Yine körinicek maña eyitgil (BH, 263).

*Ķaçan kim diledi erse ol łag̉a $a \dot{g} ı c ̧ a k$ İsmāóđil’i anuñ üzre k,urbān k̦1lısar erdi (BH, 143).

*Yā Meryem, sen cühūźları köriçek oruçmen digil (BH, 101).

-AsI

Gelecek zaman ifade eden bu ek Eski Anadolu Türkçesinde şekil ve zaman eki durumuna da geçmiştir. Eskiden - $\dot{g} a s ı /-g e s i$ şeklinde olan bu ekin - $\dot{g} a$, -ge gelecek zaman sifat-fiil eki ile $-s I$ iyelik ekinin birleşmesinden çıktığı anlaşılmaktadır (Ergin, 2003: 337). Karahanlı, Kıpçak ve Eski Anadolu Türkçesinde - AsI şeklinde kullanılmıştır. Harezm Türkçesinde - AsI şekline ek olarak GAsI ve -esü şekilleri de görülmüştür (Argunşah ve Yüksekkaya, 2019: 205).

-AsI eki BH'de hem gelecek zaman eki hem de sıfat-fiil eki olarak sıklıkla kullanılmıştır:

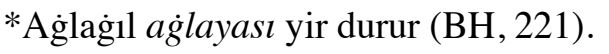

*Daķı ne kim yir yüzinde durası erse yiyesiden, keyesiden, içesiden dükelin beyān k̦ılmış erdi (BH, 105).

*Kaçan kim sökellik vaǿdesi yitse ķul oñalası vaķtı bolsa melik celle celāluhu aydur ol ferişteye (BH, 188).

*Bir nesneyi dölendüresi yirden düşürmeklik ve düşüresi yirde dölendürmeklik muǿcizātlardan durur (BH, 284).

Bu ekin Harezm Türkçesinde kullanılan -GAsI şekline BH'de de rastlanmıştır:

*Melik taǿālā, Vaĥş̧ Müsülmān bolġasın bilür erdi (BH, 293).

*Dökilgesi dükel yılduz bu felekden

Andayuk, kim yaġar erse kökden dolu (BH, 71).

\section{-DUk}

Geçmiş zaman ifade eden ve çok kullanılan sıfat-fiil eklerinden biridir. Bu ekin iyelik eki almayan şekilleri fazla kullanılmaz. Kullanış sahasına hemen hemen daima iyelik ekli şekilleri ile çıkar ve böylece en geniş ölçüde kullanılır (Ergin, 2003: 335). Karahanlı Türkçesinde bu ek -DUk, -tık şeklindedir (Argunşah ve Yüksekkaya, 2019: 81). Harezm Türkçesinde -DUk (Argunşah ve Yüksekkaya, 2019: 206); Kıpçak Türkçesinde -DIk, -DUk şekillerinde kullanılan ek, Eski Anadolu Türkçesinde ünsüz uyumuna dâhil olmayarak - $d U k$ şeklini almıştır (Gülsevin, 2011: 123).

BH'de ise bu ek ünsüz uyumuna dâhil bir biçimde yuvarlak ünlülü kullanılmıştır. Bu yönüyle Karahanlı, Harezm ve Kıpçak Türkçesi ile benzeşmektedir:

*Ve ol kimse kim sak,ınmasa bu ayıttuķumuz sevēābı bulmaya (BH, 59).

*Yine Mekke'de ћalk üküş a ġlaşduķı içün Mekke didiler (BH, 81).

*ǿ Āşıklar darttugiını dartmaya ķanlı (BH, 210).

*Tañrı sevdügi kimse assı eylese kerek ne kim ziyān?

$-\mathbf{m I s ̧}$ 
Geçmiş zaman ifade eden bu ekin eskiden sadece düz ünlülü şekilleri vardı. Ünlü uyumuna son devirlerde bağlanmıştır. Şekil ve zaman eki durumuna geçen sıfat-fiil eklerinden biridir (Ergin, 2003: 335). Türkçenin bütün tarihi dönemlerinde sıklıkla kullanılan bu ek, Karahanlı, Harezm, Kıpçak ve Eski Anadolu Türkçesi dönemlerinde düz ünlülü kullanımını devam ettirmiştir.

BH'de de bu ek, Türkçenin tarihi dönemlerindeki gibi - $m I s ̧ s ̧$ şeklindedir:

* Ol opranmış tenler ve kurımış süñükler ve yırtılmış deriler ve dağılmış saçlar ve kesilmiş tamarlar ve üzilmiş etler ve śoġlmış közler ve ayrılmış endāmlar hak,k, içün kim minüm buyrugium birle bir demde dirileler ve minüm hażretüme keleler (BH, 134).

* Ölmiş yirler dirilür, beti bozılmış yirler bezenür $(\mathrm{BH}, 130)$.

-An

Geniş zaman ifade eden bu ek, Eski Türkçede $-g A n$ şeklinde idi. Şekil ve zaman eki durumuna geçmeyen ek, eskiden beri sıklıkla kullanılmıştır (Ergin, 2003: 334). Karahanlı Türkçesinde $-g A n$ ve az da olsa $-A g A n$ şekillerindedir (Hacieminoğlu, 2019: 167-68). Harezm Türkçesinden itibaren ekteki $g$ ünsüzünün düşerek ekin $-A n$ şekline geçtiği görülür. Harezm Türkçesinde - $g A n$, -ķan ve $-A n$ ekleri birlikte kullanılmıştır (Argunşah ve Yüksekkaya, 2019: 206). Kıpçak Türkçesinde -gAn, -An kullanımı devam etmiştir (Argunşah ve Yüksekkaya, 2019: 345). Eski Anadolu Türkçesinde ise bu ek sadece - $A n$ şeklindedir (Gülsevin, 2011: 124).

BH'de ise ek çoğunlukla -An şeklindedir. Ekin, Karahanlı, Harezm ve Kıpçak Türkçesindeki - $g A n$ şeklindeki kullanımına BH'de az da olsa rastlanmıştır:

*Dükeli halḳa rūzị biren Raĥmān durur (BH, 40).

*Bu yıl togan erkege yine yıl toġan dişiyi birgil (BH, 139).

*Ey dün kün dürişüp dünyā direnler $(\mathrm{BH}, 167)$.

*Bir yıldan berü mescide barmayanlar bu ayda Çalap łapusına kelürler $(\mathrm{BH}, 88)$.

*Sizler ķamu danuķsiz kim sizleri yaratġan yaluñuz durur $(\mathrm{BH}, 177)$.

*Kemide Nūĥ erdi ayġan biǿsmiǿllāh

Hüdhüd biti iltür erdi Belkịs dapa (BH, 305).

-gUçI/-gUcI

Bu ekler - $g U$ sıfat-fiil ekinin üzerine getirilen yapım ekleri ile genişletilmiş olan eklerdir. An sıfat-fiil eki ile aynı işlevde kullanılır (Hacieminoğlu, 2019: 169). Sadece Karahanlı Türkçesinde rastladığımız bu sıfat-fiil eki BH'de de aynı işleviyle kullanılmıştır:

*Sen bir ķulsañ fermān dutġuçı ve men bir ķulmen fermān yirine ketüriçi (BH, 226). $(\mathrm{BH}, 115)$.

* Meger ol eve kirmesler kim anda hamr içgüçi bolsa ve yā ata, ana köñlin incitmiş bolsa

*Ya tartdum, dir. Fartgiucı bolur (BH, 225).

*Ve eger śabr kıılur erseñiz ol yigrek durur śabr ķılġuçılara (BH, 293).

Yine - $g U$ sıfat-fiil ekiyle oluşturulan ve Karahanlı Türkçesinde görülen - $g U s I$ sıfat-fiil eki de BH'de bir defa kullanılmıştır:

*Tañrınuñ baśịir adı başlag̉usı durur, sin semįø adı başlagiusı durur (BH, 302).

\subsubsection{Behcetü'l-Hadâik’taki Zarf-Fiiller:}


Menfilik ifade eden bir zarf-fiil ekidir. Eski Türkçede ek, -mAdIn şeklinde idi. Batı Türkçesine de bu şekilde geçmiş, Eski Anadolu Türkçesinde uzun müddet böyle kullanıldıktan sonra Eski Anadolu Türkçesinin sonlarında -mAdAn şeklini almıştır (Ergin, 2003: 342-343). Karahanlı Türkçesinde bu ek, -mAdIn, -mAdI ve -mAyIn şekillerindedir (Hacieminoğlu, 2019: 174). Harezm Türkçesinde, Eski Türkçe ve Karahanlı Türkçesinde kullanılan -mAtI/-mAdI şekilleri dışındaki -mAdIn ve -mAyIn kullanımları devam etmiştir (Argunşah ve Yüksekkaya, 2019: 207). Kıpçak Türkçesinde bu ekin sadece -mAyIn şekli kullanılmıştır (Argunşah ve Yüksekkaya, 2019: 347). Eski Anadolu Türkçesinde ise bu ek -mAdIn ve -mAdAn şeklindedir (Şahin, 2018: 74).

Karahanlı, Harezm ve Eski Anadolu Türkçesindeki -mAdIn şekli BH'de de sıklıkla kullanılmıştır:

*Dürlü eylük eylegil sen irmedin ośanmadın

Ārzular ersen sen anda ĥ̄ur boynın ķuçmaġa (BH, 45).

*Yā müǿmin, sen ol yüki boynuñdan kidermedin yitmiş yıllık, yazuķı dįvānuñdan kiderürmen $(\mathrm{BH}, 231)$.

*Oruç dutup Tañrı Łāǿatın k̦ılmasa mađ́śiyet uyuzı oñalmadın yazuġı yarlıġanmadın kalur $(\mathrm{BH}, 280)$.

*ǿ̄̄ḳil ol durur kim ölmedin ilerü ölüm berkin ḳılmış bola ve iş ser-ancāmın bilmiş bola

\section{-InçA}

Hareket hâlinin ortaya çıktığı zamanı göstermek için kullanılan zarf-fiil ekidir. Eski Türkçede bu ek -gInçA şeklinde idi. Bu bünyesi ile ekin -gIn yapım eki ile -çA eşitlik ekinin birleşmesinden doğduğu anlaşılmaktadır. Batı Türkçesine ek -InçA şeklinde geçmiş, Eski Anadolu Türkçesinde uzun zaman bu şekilde kullanılmıştır. Sonradan Osmanlıcada ek c'li şekle sokularak ve ünlü uyumuna bağlanarak bugünkü şekiller ortaya çıkmıştır (Ergin, 2003: 341-342). Karahanlı Türkçesinde -gInçA şeklinde (Hacieminoğlu, 2019: 174) kullanılan ek Harezm Türkçesinde -InçA şeklini almıştır. Ayrıca $-g I n c ̧ A,-g U n c ̧ a,-k U n c ̧ A,-g U c ̧ A$, -gimçe ve $-g U m c ̧ A$ şekillerine de yine Harezm Türkçesinde rastlanmıştır (Argunşah ve Yüksekkaya, 2019: 207). Kıpçak Türkçesinde gInçA ve -gUnçA kullanımı devam etmiştir (Argunşah ve Yüksekkaya, 2019: 346). Eski Anadolu Türkçesinde ise ek, -IncA şeklindedir (Gülsevin, 2011: 126).

BH'de bu ek Harezm Türkçesindeki -InçA şekliyle kullanılmıştır:

*Biz bu işi bitürinçe atam sü dirsün $(\mathrm{BH}, 151)$.

*Bellü bilgil kendüzüñni suçlu ķulsın suçlu ķul

Suçlu suçı yarlıganmas suçına tevbe ķılınça $(\mathrm{BH}, 46)$.

* ǾAraśāt halḳı bitilerin oḳıyınça ve hisābların birinçe ve Ǿamelleri terāzūya dartılınça bular anda dursunlar, dünyā arnuġ̀ndan diñlesünler (BH, 70).

*Dünyā sevgülügi süçüsin içen kimse gūra kirmeyinçe ayılmas ve gūrda tevbe ḳılsa ķabūl bolmas (BH, 167).

Eski Anadolu Türkçesinde zarf-fiil eki olarak kullanılan - $d U g \operatorname{Inc} A$ yapısına BH'de de rastlanmıştır:

*Ol taķı kim erdi kim saġdın śoldın segirdür irdüginçe?

*Degme bir hamle ḳıldugiınça Melik Ǿazze ve celle müǿminler köñline bir nažar ḳılur (BH, 291). 


\section{-bAn/-UbAn}

Bu ekler fonksiyon bakımından $-A r A k$ ekinden farksızdır. Eski Türkçenin başında $-p A n$ şeklinde kullanılan ekin - $p$ zarf-fiil ekine - $A n$ unsurunun eklenmesiyle ortaya çıktığ 1 söylenebilir. Bu zarf-fiil eki sonradan - $p$ zarf-fiil ekinin gelişme seyrine uygun olarak Batı Türkçesinde başına ünlü almış ve $p$ 'si de iki ünlü arasında $b$ olduğu için $-U b A n$ şekline geçmiştir (Ergin, 2003: 345). Karahanlı Türkçesinde $-b A n /-p A n,-U b A n /-U p A n$ ve $-I b A n /-I p A n$ şekillerinde kullanılan ek (Argunşah ve Yüksekkaya, 2019: 83) Harezm Türkçesinde -IbAn, -UbAn, -ban şekillerindedir (Argunşah ve Yüksekkaya, 2019: 207). Kıpçak Türkçesinde ise bu ekin sadece -bAn şekli görülür (Argunşah ve Yüksekkaya, 2019: 345). Özellikle Eski Anadolu Türkçesinde sıklıkla kullanılan bu ek, -UbAn ve -UbAnIn şekillerindedir (Gülsevin, 2011: 133).

BH'de bu ek, hem Karahanlı, Harezm ve Kıpçak Türkçesinde ortak bir biçimde kullanılan $b A n$ şekli ile hem de özellikle Eski Anadolu Türkçesinde sıklıkla kullanılan -UbAn şekli ile kullanılmıştır:

*Maǿśsiyet işden ķaçalar, ag̉laban hasret yaşın saçalar (BH, 56).

*Körür müseñ eyā ḳul bu Ǿacebni

Minüm ayum diben birdi recebni (BH, 52).

*Bulardan k,alanı dagılluban źerre bolur (BH, 218).

*Kanı ol Øömrüñüze küvenüben

Dostlar birle Ǿaceb łatlu keçdügünüuz (BH, 259).

\section{$-\mathbf{p} /-\mathbf{U p}$}

Eski Türkçede - $p$ şeklinde kullanılan ek, Batı Türkçesine geçerken önündeki yardımcı ünlünün, ekin bünyesine dâhil zannedilmesiyle Batı Türkçesinde iki sesli olmuştur. Batı Türkçesinin başlarında $p$ tesiriyle ekin ünlüsü daima yuvarlak ünlülü olmuştur. Eski Anadolu Türkçesinde yuvarlak ünlülü kullanılan ek, ancak Osmanlıca içinde ünlü uyumuna dâhil olmuştur (Ergin, 2003: 340-341). Karahanlı Türkçesinde - $p,-I p$ ve $-U p$ şeklinde kullanılan ekin (Hacıeminoğlu, 2019: 171) Harezm ve Kıpçak Türkçesinde de bu kullanımları devam etmiştir (Argunşah ve Yüksekkaya, 2019: 207, 347). Eski Anadolu Türkçesinde ise ek, sadece -Up şeklindedir (Gülsevin, 2011: 133).

BH'de bu ek hem Karahanl1, Harezm ve Kıpçak Türkçesindeki gibi - $p /-I p$ olarak hem de Eski Anadolu Türkçesindeki gibi - Up olarak kullanılmıştır:

*Keldi berāt düni ķul bilüñ bekrü banġıl

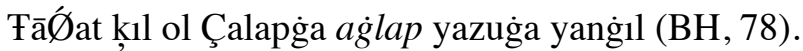

*Eger cevāb birmes erse gūr iki yañadın ḳısar, eyegülerin bilip iki büküp k,yāmete degin Ǿaźāb ķ1lur (BH, 228).

*Ve biribirine doķınup k,avuz bolsa, havāya dökse (BH, 112).

*Bu iki daǾvịcinüñ birisi sözin diñlep birisi sözin ḳomaķ revā degül (BH, 239).

\section{-dUkçA}

$-d I k$ sıfat-fiil eki eskiden $-d U k$ şeklinde idi. Bu $-d U k$ sıfat-fiil ekine $+c ̧ A$ eşitlik eki getirilerek - $d U k c ̧ A$ şeklini almış ve bu şekil zarf-fiil olarak kullanılmıştır (Ergin, 2003: 336). Bu ek, Kıpçak Türkçesinde - $d U k c ̧ A$ olarak (Argunşah ve Yüksekkaya, 2019: 346) ve Eski Anadolu Türkçesinde - $d U k c ̧ A /-d U k c A$ olarak (Gülsevin, 2011: 131) kullanılmıştır.

BH'de bu zarf-fiil eki - $d U k c ̧ A$ şeklindedir ve fazla kullanılmamıştır: 
*Yine Cebraǿil Ǿaleyhi's-selām beytü'l-Ǿizzet evinden āyet āyet, sūre sūre, necm necm hāaet boldukça yigirmi yılda Muhammed Muśtafā'ya indürdi (BH, 95).

*Kelüñ, körüñ sekiz uçmaķ Ǿatịd körüñ, temāşā bak,dukça cedįd keleçi diñleñ (BH, 229). (BH, 251).

*Ķamu kemiler śuva łolsa aşag̉a çöker ol kemi kim bulıt durur śuva dolduķ̧̧a yoḳaru çıķar

BH'de bu ekin ünsüz uyumuna girdiği az sayıda örnek de bulunmaktadır:

*Bular yattuķ̧̧a dostlarg̉a şerị́

-ken

$i$ - fiilinin zarf-fiil ekidir. $i$ - fiilinin $i$-ken'den başka zarf-fiil şekli yoktur. $i$ - kökü düşüp zarffiil ekleştiği zaman bile -ken değişmeyerek ünlü uyumu dışında kalır (Ergin, 2003: 346). Karahanlı, Harezm, Kıpçak ve Eski Anadolu Türkçesinde -ken yapısı aynı şekliyle kullanılmıştır.

BH'de de -ken zarf-fiil eki sıklıkla kullanılmıştır:

*Cān birürken peyk-i hażret Cebrāǿil'den

Ümmetinini śorar erdi cān muñında (BH, 271).

*Eylak, erken ol dostluk, kesmes (BH, 43).

*Bir kün MuǾ̄āviye, Yezịd og̉lan erken egnine kötürüp kelür erdi (BH, 150).

$-\mathbf{A} /-\mathbf{I} /-\mathbf{U}$

Türkçede eskiden beri kullanılan bu ekler bugün yalnız birleşik fiillerde görülmektedir. Önceden $-I$ ve $-U$ şeklinde kullanılan bu zarf-fiil ekleri sonradan $-A$ şekline geçmiştir. $-I$ ve $-U$ zarffiil ekleri eskiden tek başına veya tekrar şeklinde zarf olarak da bol bol kullanılmıştır (Ergin, 2003: 340). Karahanlı Türkçesinde $-A$, $-I$ ve $-U$ şekillerinde (Hacieminoğlu, 2019: 172); Harezm Türkçesinde $-A$ ve $-U$ şekillerinde (Argunşah ve Yüksekkaya, 2019: 207) ve Kıpçak Türkçesinde yine $-A,-I$ ve $-U$ şekillerinde (Argunşah ve Yüksekkaya, 2019: 346) kullanılmıştır. Eski Anadolu Türkçesinde de $-A$, $-I$ ve $-U$ şekilleri kullanılmaya devam etmiştir (Gülsevin, 2011: 130).

BH'de bu zarf-fiil ekleri çoğunlukla birleşik fiillerde kullanılmıştır. Yalnızca $-U$ ekinin tek başına kullanıldığı örnekler de bulunmaktadır:

*Śahāābelerüñ közlerine yaş tola keldi (BH, 110).

*Elinde bir deve yide keldi (BH, 244).

*Ĥak taǿālā ol kuluñ teninde nice dü barısa degme bir ḳılına uçmak içinde bir derece ksaldurı bire (BH, 146).

*Çalap, śuvı bulara yöridi birür (BH, 130).

BH'de $-U$ zarf-fiil eki tek başına kullanıldığında ifadeye çoğunlukla -ArAk zarf-fiilinin kattığı anlamı vermektedir. Bu özelliğiyle Karahanlı, Harezm ve Kıpçak Türkçesindeki - $U$ zarf-fiil kullanımlarıyla benzerlik göstermektedir:

*İste rūzuñnı helālden bir Çalapġa yalvaru

Birge rūzuñnı helālden herze loḳma yutmag̀ıl (BH, 162).

* Oruç ayı kelür uş raĥmetin üleşdürü

Ķarşu bar ķul aña sen köñlüñi ulaşduru (BH, 82).

-dI erse:

www.turkishstudies.net/language 
Görülen geçmiş zaman eki - $d I$ ile $e r$ - fiilinin şart çekiminin birleşmesiyle ortaya çıkan ve ifadeye zaman anlamı katan bir zarf-fiil ekidir. Harezm Türkçesinde kullanılan (Argunşah ve Yüksekkaya, 2019: 206) bu zarf-fiil eki BH'de de sıklıkla kullanılmıştır:

*Kaç̧an āz̨ine namāzına dirildiler erse bu dirnek ol dirnekden ulu boldı (BH, 119).

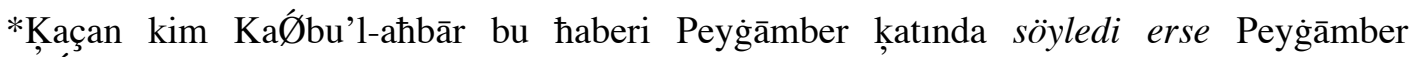
śalla'llāhu Ǿaleyhi ve sellem yüzin kök dapa döndürdi (BH, 110).

*Kaçan kim Peygaāmber dünyādan dulındı erse ol og̉lan daşra çık,dı (BH, 124).

*Kaçan kim hāl anuñ üzre döndi erse Peyġāmber anı sevmes boldı (BH, 211).

-AlI:

Türkçede eskiden beri kullanılan bu zarf-fiil eki Eski Türkçede -gAlI şeklinde idi. Batı Türkçesine - $A l I$ şeklinde geçmiştir. Eski Türkçede $-m A k$ için anlamı ile kullanılan bu ek, Batı Türkçesinde -den beri anlamını taşımıştır (Ergin, 2003: 342). Karahanlı, Harezm ve Kıpçak Türkçesinde -gAlI şeklinde kullanılan bu ek, Eski Anadolu Türkçesinde - AlI şeklindedir (Gülsevin, 2011: 127).

BH'de de bu ek -AlI şeklindedir ve çok sık kullanılmamıştır:

*Daķı nice uzun yaşar erseñ ucı ölüm durur Ĥaķ yolın saña bildüreli demi durur (BH, 273).

*Velākin delim boldı men bulara raĥmet k, klalı $(\mathrm{BH}, 186)$.

Eski Anadolu Türkçesi ve Osmanlıcada -AlI zarf-fiil ekine ayrılma hâl eki getirildiğinde bu ekin son ünlüsünün düşürüldüğü görülür (Ergin, 2003: 342). Bu kullanıma da BH'de bir defa rastlanmıştır:

*Men saña müştāk, boldum ol k,ocayı körelden berü (BH, 273).

\section{Sonuç}

Karışık dilli eserler içerisinde karışı dilliliği en iyi temsil eden eser olarak kabul edilen Behcetü'l-Hadâik'ta fiilimsi eklerinin kullanım özellikleri de bu nitelemeyi doğrulamaktadır. Nitekim eserde hem Karahanl, Harezm ve Kıpçak Türkçesine hem de Eski Anadolu Türkçesine özgü kullanımlar bulunmaktadır. Bunları şu şekilde sıralamak mümkündür:

a. Hem Karahanlı Türkçesinde hem de Behcetü'l-Hadâik'ta ortak bir biçimde kullanılan fiilimsiler şunlardır: $-m A,-m A k,-I_{S ̧} /-U_{S},-r /-A r /-I r /-U r,-m A s,-A s I,-D U k,-m I s ̧,-A n /-g A n$, $g U c I / g U c ̧ I,-g U s I,-m A d I n,-b A n /-U b A n,-p /-I p /-U p$, -ken, -A/-I/-U. Bu eklerin sayıs1 27'dir.

Bu eklerden - $g U c I /-g U_{c ̧} I$ ve $-g U s I$ ekleri sadece Karahanlı Türkçesi ve BH'de ortaktır:

*Sen bir ķulsañ fermān dutg்uçı ve men bir ķulmen fermān yirine ketüriçi (BH, 226).

*Tañrınuñ baśịr adı başlag̉usı durur, sin semįǿ adı başlag̉usı durur (BH, 302).

b. Harezm Türkçesi ve Behcetü'l-Hadâik'ta ortak bir biçimde kullanılan fiilimsiler de bulunmaktadır. Bunlar, $-m A$, $-m A k,-I S \zeta /-U s,-r /-A r /-U r,-m A s,-A s I /-G A s I,-D U k,-m I S,,-A n /-g A n$, $m A d I n,-b A n /-U b A n$, -InçA, - $p /-I p /-U p$, -ken, $-A /-U$, -dI erse ekleridir. Bu eklerin sayıs1 25'tir.

$\mathrm{Bu}$ eklerden -GAsI, -InçA ve -dI erse ekleri sadece Harezm Türkçesi ve Behcetü'lHadâik'ta ortaktır:

*Dökilgesi dükel yılduz bu felekden

Andayuk kim yagar erse kökden dolu (BH, 71).

*Biz bu işi bitürinçe atam sü dirsün $(\mathrm{BH}, 151)$. 
*Ķaçan kim Peygaāmber dünyādan dulındı erse ol og̉lan daşra çıķdı (BH, 124).

c. Kıpçak Türkçesi ve Behcetü'l-Hadâik'ta ortak bir biçimde kullanılan fiilimsi ekleri ise şu şekildedir: $-m A,-m A k,-I S \zeta /-U S$, , $-r /-A r /-I r /-U r,-m A s,-I c ̧ A k,-A s I,-D U k,-m I s ̧,-A n /-g A n,-b A n,-$ $p /-I p /-U p$, $-d U k c ̧ A$, $-k e n,-A /-I /-U$. Bu eklerin sayısı 24'tür.

Bu eklerden sadece -IçAk eki Kıpçak Türkçesi ile Behcetü'l-Hadâik'ta ortaktır:

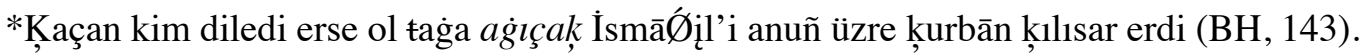

d. Eski Anadolu Türkçesi ile Behcetü'l-Hadâik'ta ortak bir biçimde kullanılan fiilimsiler şu şekilde sıralanabilir: $-m A,-m A k$, $-I_{S ̧} /-U_{S},-m A k l I k,-r /-U r,-I c A k,-A s I,-d U k,-m I s ̧,-A n,-m A d I n$, $d U g I n c A,-U b A n,-U p$, -dUkçA, -ken, -A/-I/-U, -AlI, -AldAn. Bu eklerin sayısı 23 'tür.

Ortak kullanılan eklerden -mAklIk, -IcAk, -dUgIncA ve -AldAn ekleri Eski Anadolu Türkçesi ile Behcetü'l-Hadâik'ta ortaktır:

*Ve KaǾbe yapılup tamām bolmaḳlığı bu on kün içinde erdi (BH, 134).

*Ve ol k,ızlar kim anadan dogiıcak, ǾArablar anı dirile külidiler (BH, 201).

*Ol taķı kim erdi kim saġdın śoldın segirdür irdüginçe? (BH, 247).

*Men saña müştāk, boldum ol k,ocayı körelden berü (BH, 273).

Behcetü'l-Hadâik'ta -r / - Ar / -Ir / -Ur sıfat-fiil eki Karahanlı ve Kıpçak Türkçesindeki kullanım şekilleriyle karşımıza çıkmaktadır. Bu ek, Eski Anadolu Türkçesinde yuvarlaklaşmanın etkisiyle $-r /-U r$ şeklinde; Harezm Türkçesinde ise $-r /-A r /-U r$ şeklindedir. Ekin düz ünlülü kullanımına Karahanlı ve Kıpçak Türkçesinde rastlanmıştır: (BH, 208).

*Yörir ayak, dutar el k̦ıldum, işidür k,ulak, söyler dil ķıldum, körür köz, bilür köñül k,ıldum

Behcetü'l-Hadâik'ta - $m A s$ sıfat-fiil ekinin - $m A z$ kullanımı yoktur. Bu özelliğiyle Karahanlı, Harezm ve Kıpçak Türkçesiyle benzerlik gösterir:

*Bu kerekmes yirde harf k,omaķa iǿcāz lāzım durur (BH, 284).

-dUk sıfat-fiil eki Behcetü'l-Hadâik'ta ünsüz uyumuna dâhil bir biçimdedir. Aynı ek Eski Anadolu Türkçesinde uyum dışıdır. Bu özelliği itibarıyla ek, Karahanlı, Harezm ve Kıpçak Türkçesindeki kullanımıyla örtüşmektedir:

*Ve ol kimse kim sak,ınmasa bu ayıttuķumuz ŝevābı bulmaya (BH, 59).

-An sıfat-fiil eki Eski Anadolu Türkçesinde de kullanılmıştır. Fakat Behcetü'l-Hadâik'ta ekin bu şekli ile birlikte $-g A n$ şekline de rastlanmıştır. Bu kullanım da Karahanlı, Harezm ve Kıpçak Türkçesi ile örtüşmektedir:

*Sizler kamu danuķsiz kim sizleri yaratgan yaluñuz durur $(\mathrm{BH}, 177)$.

Eski Anadolu Türkçesinde - UbAn şeklinde kullanılan zarf-fiil ekinin Karahanlı, Harezm ve Kıpçak Türkçesinde - $b A n$ şekli de bulunmaktadır. - $b A n$ kullanımı Behcetü'l-Hadâik ile ortaktır:

*MaǾśiyet işden ķaçalar, ag̉laban ĥasret yaşın saçalar (BH, 56).

Eski Anadolu Türkçesinde sadece yuvarlak ünlülü - $U p$ şeklinde kullanılan zarf-fiil ekinin $p$ şeklindeki kullanımı Karahanlı, Harezm ve Kıpçak Türkçesi ile Behcetü'l-Hadâik'ta ortaktır:

*Bu iki daǾvịcinüñ birisi sözin diñlep birisi sözin ķomaķ revā degül (BH, 239). 
- $U$ zarf-fiil eki, tek başına kullanıldığında ifadeye $-A r A k$ anlamı katmaktadır. Bu ekin bu şekliyle kullanımına Karahanlı, Harezm ve Kıpçak Türkçesi ile Behcetü'l-Hadâik’ta da rastlanmıştır:

*İste rūzuñnı helālden bir Çalapġa yalvaru

Birge rūzuñnı helālden herze loḳma yutmaġıl (BH, 162).

Behcetü'l-Hadâik'ta Karahanlı Türkçesi ile 2; Harezm Türkçesi 3; Kıpçak Türkçesi ile 1 ve Eski Anadolu Türkçesi ile 4 ortak biçimde kullanılan fiilimsi tespit edilmiştir. Ayrıca, Karahanlı, Harezm ve Kıpçak Türkçesinde ortak bir biçimde kullanılan 7 fiilimsiye Behcetü'l-Hadâik'ta da rastlanmıştır. Behcetü'l-Hadâik'ta Eski Anadolu Türkçesindeki fiilimsilere özgü kullanımlar, Karahanlı, Harezm ve Kıpçak Türkçesine göre daha azdır. Bu durum, 14. yüzyılın hemen başında istinsah edilen Behcetü'l-Hadâik'ın Bursa nüshasının, Anadolu coğrafyasında doğup büyüyen kişiler tarafindan değil de Anadolu'ya göç eden Türkler tarafindan yazıldığı ihtimalini kuvvetlendirmektedir.

\section{Kaynakça}

Akar, A. (2017). Türk dili tarihi. İstanbul: Ötüken Yayınları.

Argunşah, M., \& Sağol Yüksekkaya, G. (2019). Karahanlıca Harezmce Klpçakça dersleri. İstanbul: Kesit Yayınları.

Ata, A. (2014). Harezm-Altınordu Türkçesi. Ankara: Ankara Üniversitesi Yayınları.

Atalay, B. (2018). Divanü Lugat-it Türk (Dizin). Ankara: Türk Dil Kurumu Yayınları.

Bayraktar, N. (2018). Türkçede fiilimsiler. Ankara: Türk Dil Kurumu Yayınları.

Bulduk, T. B. (2019). Behcetü'l-Hadâik ve Kıssa-y1 Yusuf' taki Kip Ekleri Üzerine Karşılaştırmalı Bir İnceleme. Tarih Okulu Dergisi, 1956-1977. http://dx.doi.org/10.29228/joh.39926

Canpolat, M. (2018). Behcetü'l-Hadaik Fî Mev'izati'l-Halaik. Ankara: Türk Dil Kurumu Yayınları.

Demir, N. (2019). Türkçe ses ve biçim bilgisi. Ankara: Altınordu Yayınları.

Erdem, M., \& Sarı, M. (2010). Karışık Dilli Eserlere Farklı Bir Bakış. Turkish Studies International Periodical For the Languages, Literature and History of Turkish and Turkic, $390-415$.

Ergin, M. (2003). Türk dil bilgisi. İstanbul: Bayrak Basım / Yayım / Tanıtım.

Erol, H. A. (2014). Eski Türkçeden Eski Anadolu Türkçesine anlam değişmeleri. Ankara: Türk Dil Kurumu Yayınları.

Gülsevin, G. (2011). Eski Anadolu Türkçesinde ekler. Ankara: Türk Dil Kurumu Yayınları.

Hacıeminoğlu, N. (2019). Karahanlı Türkçesi grameri. Ankara: Türk Dil Kurumu Yayınları.

Korkmaz, Z. (2013). Türkiye Türkçesinin temeli Oğuz Türkçesinin gelişimi. Ankara: Türk Dil Kurumu Yayınları.

Özkan, M. (2000). Türk dilinin gelişme alanları ve Eski Anadolu Türkçesi. İstanbul: Filiz Kitabevi.

Şahin, H. (2015). Eski Anadolu Türkçesi. Ankara: Akçağ Yayınları.

Timurtaş, F. K. (1994). Eski Türkiye Türkçesi. İstanbul: Enderun Kitabevi.

Toparlı, R., Vural, H., \& Karaatlı, R. (2014). Kıpçak Türkçesi sözlüğü. Ankara: Türk Dil Kurumu Yayınları.

Türk, V., Doğan, Ş., \& Şerifoğlu, Y. (2018). Eski Anadolu Türkçesi dersleri. İstanbul: Kesit Yayınları.

Ünlü, S. (2012). Harezm-Altınordu Türkçesi sözlüğü. Konya: Eğitim Kitabevi.

Ünlü, S. (2012). Karahanlı Türkçesi sözlüğ̈̈. Konya: Eğitim Kitabevi. 